\title{
Spatial and temporal variability of precipitation in East China from 1880 to 1999
}

\author{
Weihong Qian ${ }^{1, *}$, Zicheng $\mathrm{Yu}^{2}$, Yafen $\mathrm{Zhu}^{1}$ \\ ${ }^{1}$ Monsoon and Environment Research Group, School of Physics, Peking University, Beijing 100871, China \\ ${ }^{2}$ Department of Earth and Environmental Sciences, Lehigh University, 31 Williams Drive, Bethlehem, Pennsylvania 18015, USA
}

\begin{abstract}
In this study, updated seasonal precipitation time series for 1880-1999 from 71 sites in East China were analyzed to identify spatial and temporal precipitation variability, to document possible climate regime changes, and to place the extreme climate events and disasters in the historical context of the last century. The records were constructed using a combination of historical documents and instrumental records. During the last 100 yr (1900-1999), dry and wet climate anomalies based on 3 decade averaged precipitation tended to initiate in NW China and shifted eastward or southeastward. In the spring and winter seasons, dry or wet anomaly centers first appeared in NW China and shifted eastward to North China and NE China. In the summer and autumn seasons, dry or wet centers also occurred first in NW China and shifted southeastward to the central and lower Yangtze Valley regions and South China. Annual mean precipitation series from 6 regions showed that the 1920s were the driest decade in East China during the last $100 \mathrm{yr}$.
\end{abstract}

KEY WORDS: Precipitation · Regime shift $\cdot$ East China $\cdot 20$ th century $\cdot$ Decadal rainfall anomalies Resale or republication not permitted without written consent of the publisher

\section{INTRODUCTION}

Most parts of China have high precipitation variability at seasonal to interdecadal timescales ( $\mathrm{Hu}$ et al. 2003, Liu et al. 2005). Extreme weather and climate events, such as anomalously dry (drought) and wet (flood) spells, have been recurrent natural disasters in China (Xu 2001). They have caused the largest economic losses among all natural disasters in 1949-1995 (Damage Report 1995). Anomalously dry events can be persistent, lasting for decades. For example, the lower Yellow River has dried up for short periods of time every year since 1972, and these became more frequent and long-lasting (>50 d) in the 1990s (Qian \& Zhu 2001). On the other hand, flooding has been more frequent during the last decade of the 20th century in the Yangtze Valley Basin (Gong \& Ho 2002). Documenting and understanding patterns of precipitation anomalies and possible climate regime shifts over the last 120 yr has important implications for projecting and mitigating possible future climate changes.
There have been a number of studies on the decadal variability of precipitation in China. For example, using the monthly mean rainfall data for summer (June-August) in 1951-1994, Hu (1997) found that the rainfall anomaly around 1977-1979 changes from above normal to below normal in the southern and southwestern parts of China. Weng et al. (1999) studied multi-scale summer rainfall variability over China and its long-term link to global sea surface temperature (SST) variability using monthly rainfall data from 160 stations from 1955-1997. They found that an abrupt shift of rainfall regime in the late 1970 s was associated with the quasi-in-phase reinforcement between the quasi-20year and quasi-40-year signals in SST. Using ground observations of daily rainfall over China during summers for the period 1961-1995, Ho et al. (2005) examined interdecadal changes of rainy events and found that central China was wetter, and northern and southern China were drier in the decades following 1979 as compared to the earlier decades. Xu 
(2001) reported that southward move of the summer monsoon rainy belt in East China started in the late 1970s and early 1980s. However, the observed precipitation data used in most of these previous studies were limited to summer and only for the past $50 \mathrm{yr}$. Therefore, it is not clear whether climate changes in the late 1970s also appeared in earlier time periods or during other seasons.

Recently, climate time-series from historical documents have become available and have been used to study climate variations in China over longer time scales. For example, Hu \& Feng (2001) analyzed the dry-wet time-series data in China for the period 1470-1997 from 65 sites and found a southward shift of dry-wet centers at centennial timescale in East China. Song (2000) used the same data from 100 sites (1470-1998) to investigate centennial changes in dryness and wetness. Qian et al. (2003b) analyzed the same dataset and found that there were 3 large variability centers of dry-wet indices occurring in North China, the middle and lower Yangtze Valley, and South China during the last 500 yr. Zhou et al. (2002) studied chaotic features of floods using data from sites in the Huaihe River Basin in the period 1470-1991. The long-term datasets used in the above mentioned analyses from 100 sites for the last 500 yr in China were mainly for summer and were semi-quantitative dry-wet indices.

In this study, we analyzed the seasonal precipitation data for the last 120 yr from 71 sites in East China to document the temporal and spatial precipitation variability and to identify possible shifts in climate regimes in different regions. Our analyses provided new insight to precipitation variations through using seasonal data and long quantitative historical data. The objectives were to provide a systematic evaluation of seasonal precipitation variability and its temporal changes in different regions of East China in order to detect spatial and temporal trends, regime shifts, or possible regularity.

\section{DATA SOURCES AND ANALYSIS METHODS}

Precipitation of 4 seasons (spring: March-May; summer: June-August; autumn: September-November; winter: December-February) from 1880 to 1998 in East China was constructed using a combination of historical documents and instrumental records. These precipitation data at 35 sites in East China were provided in Ye et al. (1998) and Wang et al. (2000) and were also used in Qian \& Zhu (2001). These seasonal precipitation data have been recently expanded by these authors to cover the period 1880-1999 for 71 sites in East China.
In China, the number of meteorological observation stations has increased dramatically over the last $120 \mathrm{yr}$, especially since the 1950s (Table 1). The sites with daily observations have increased to $>700$ since 1961 (Zhai et al. 2005, Qian \& Lin 2005). The selected 71 sites show homogeneous distribution in East China (Fig. 1), and their observational series contain data at least $10 \mathrm{yr}$ prior to 1951. Although data from some of these sites can be found in the Global Historical Climatology Network (GHCN, Peterson \& Vose 1997) and in grid format (New et al. 2000), many sites with long precipitation series starting from the 1920s or 1930s used in this study cannot be found in these data sources.

Before the availability of instrumental records, historical documents were used to derive precipitation time-series. During the Qing Dynasty (1644-1911) detailed weather information, such as rainy days and rainy hours, were recorded in government documents (i.e. 'clear and rainy records' as well as 'rain infiltration depth and snow depth') at a network of 273 adminis-

Table 1. Number of climate observation sites in China

\begin{tabular}{|rrrr|}
\hline Year & N & Year & N \\
\hline 1881 & 5 & 1931 & 47 \\
1891 & 10 & 1941 & 66 \\
1901 & 14 & 1951 & 160 \\
1911 & 26 & 1958 & 660 \\
1921 & 36 & 1961 & $>700$ \\
\hline
\end{tabular}

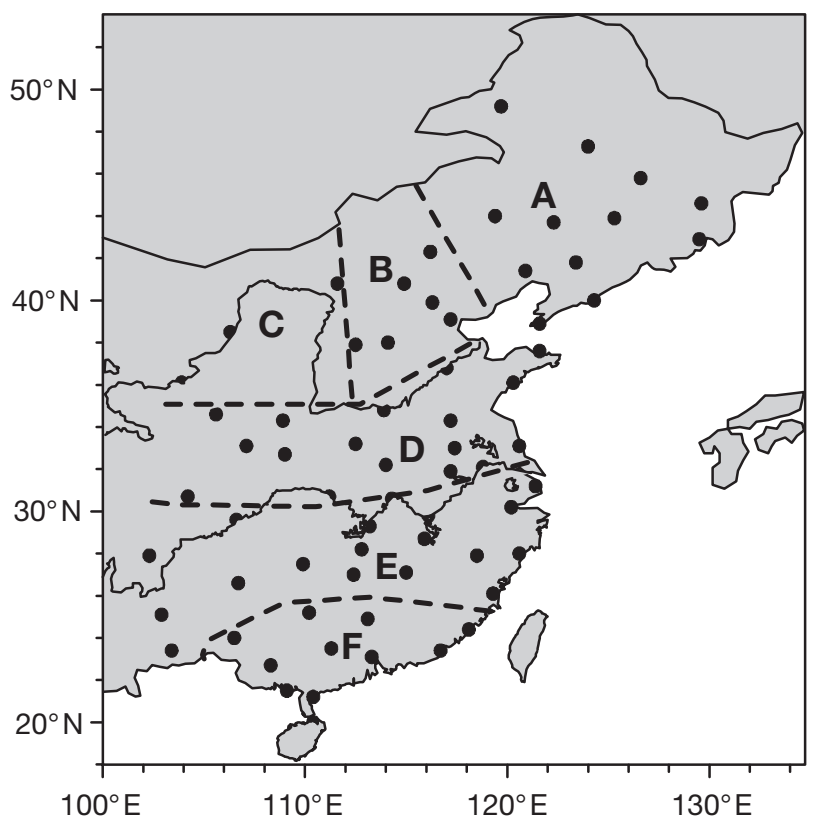

Fig. 1. Locations of 71 sites (dots) for annual and seasonal precipitation in East China and 6 regions (A: NE China, B: North China, C: NW China, D: Central China, E: Yangtze River Valley, F: South China) 
trative sites in East China (Ge et al. 2005). Dry-wet index series in East China for the last 500 yr have been widely used in previous studies (Song 2000, Hu \& Feng 2001). These series were constructed by using distribution maps of 5 dry-wet scales mainly from summer (Wang \& Zhao 1979). Wang et al. (2000) developed a method to transform seasonal semi-quantitative dry-wet scales into precipitation amounts. The transfer function was first constructed for the period 1951-1970 when both instrumental and semi-quantitative data sets are available. The established relationship was then applied to the earlier periods to derive seasonal precipitation.

We used the percentage differences between the individual $30 \mathrm{yr}$ running mean and the long-term mean of the period 1900-1999 to describe precipitation regime shifts. The percentage difference $\left(P_{c}\right)$ was calculated based on the following equation

$$
P_{c}=\left(P_{30}-P_{100}\right) / P_{100}
$$

where $P_{30}$ and $P_{100}$ are the $30 \mathrm{yr}$ and the $100 \mathrm{yr}$ (1900-1999) mean precipitation, respectively.

Considering the difference of precipitation variations in both northern and southern China, we use a the coefficient of variability (CV) to map spatial variability of annual and seasonal precipitation. CV takes into account of the actual precipitation amount to show the relative variability, i.e.

$$
C V=\frac{\sqrt{\frac{\sum_{i=1}^{n=100}\left(x_{i}-x_{0}\right)\left(x_{i}-x_{0}\right)}{n-1}}}{x_{0}}
$$

where $x_{i}$ is annual or seasonal precipitation amount from $i=1$ to $n(100) y r$ and $x_{0}$ is the annual or seasonal mean for the last $100 \mathrm{yr}$.

\section{SHIFTS IN PRECIPITATION ANOMALIES}

East China is influenced by the East Asian summer monsoon (Tao \& Chen 1987). All 71 sites used in the analysis are located in the monsoon influenced region and are distributed evenly in East China (Fig. 1). The standard deviation (SD) can indicate the absolute variations of precipitation, while the $\mathrm{CV}$ shows the relative variations of precipitation by considering the precipitation amount at a site. Large CVs of annual precipitation are located along the Yellow River Valley and in North and NE China with a value of $>25 \%$ (Fig. 2A). Seasonally, relatively large CVs in spring (40-60\%) and in winter $(70-90 \%)$ are found in North China,
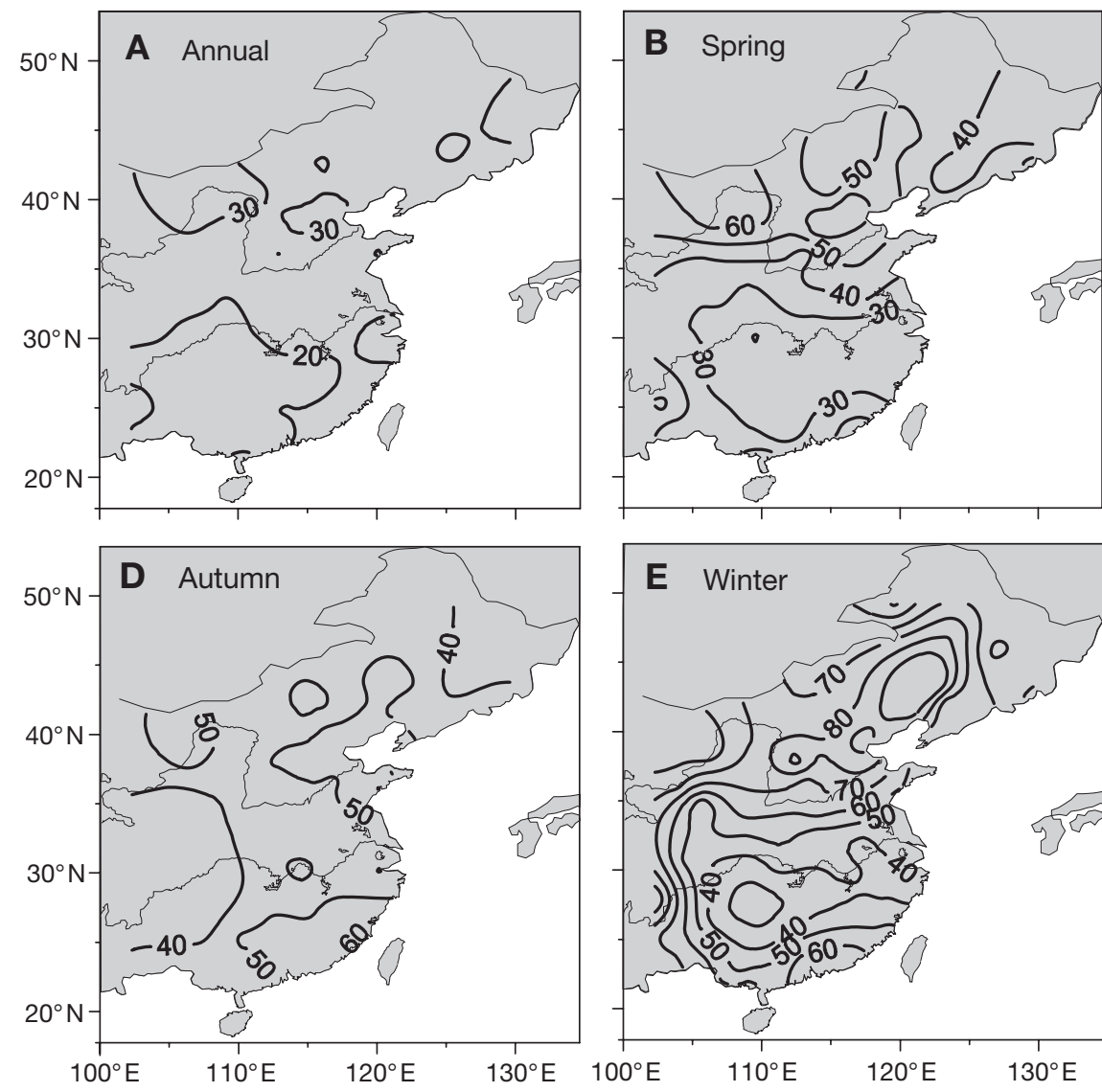

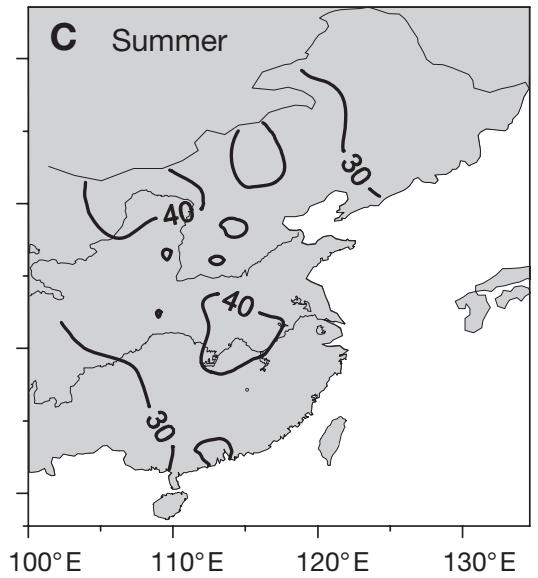

Fig. 2. Distributions of the coefficients of variability $\left(\mathrm{CV}_{\text {; }}\right.$ as percentages $)$ for (A) annual, (B) spring; (C) summer; (D) autumn; and (E) winter precipitation for the period 1900-1999 

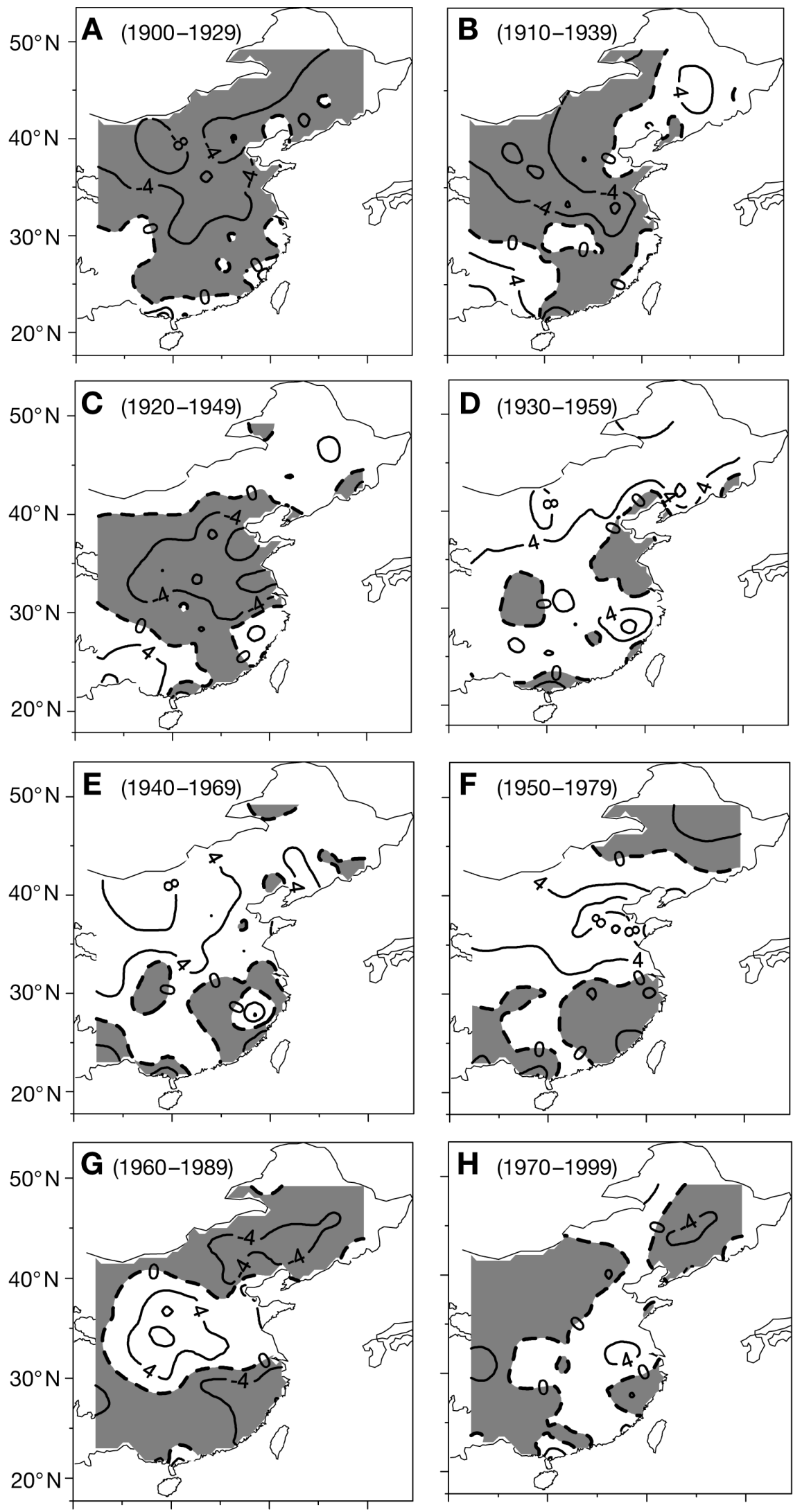

$100^{\circ} \mathrm{E} \quad 110^{\circ} \mathrm{E} \quad 120^{\circ} \mathrm{E} \quad 130^{\circ} \mathrm{E} \quad 100^{\circ} \mathrm{E} \quad 110^{\circ} \mathrm{E} \quad 120^{\circ} \mathrm{E} \quad 130^{\circ} \mathrm{E}$ while lower CVs (30-40\%) are located in southern China (Fig. 2B,E). In summer, relatively large CVs $(40 \%)$ are located in the middle Yangtze River and NW China (Fig. 2C). In autumn, large CVs are noted in many places except in the regions of SW China and NE China (Fig. 2D).

The large precipitation variability in northern China and in winter as identified by CV distributions was based on data from the entire period 1900-1999. In order to identify the temporal and spatial shifts of precipitation anomaly patterns, we show the distributions of percentage differences of the running mean for different $30 \mathrm{yr}$ periods relative to 1900-1999 (Figs. 3-7). This can indicate the possible shift of long-term climate regimes.

3.1. Annual mean. For the mean annual precipitation (Fig. 3), the largest negative percentage (anomaly) center $(-8 \%)$ is first observed in NW China (1900-1929) and then shifts eastward to the lower Yangtze Valley from the periods $1910-1939$ to $1920-1949$. The largest positive percentage $(+8 \%)$ is also first observed in NW China (1930-1959) and shifts eastward to North China (1950-1979) and southward to the central and lower Yangtze Valley (1960-1989 and 1970-1999). This shift was consistent with the longterm decreasing trend of the East Asian summer monsoon intensity index during the same period (Guo et al. 2004). Reversed distribution patterns of positive and negative change in annual precipitation appear to occur during the following periods: 1900-1929 (-) and 1940-1969 (+); 1910-1939 (-) and 1950-1979 (+); 1920-1949 (-) and 1960-1989 (+); and 1940-1969 (+) and 1970-1999 (-). The shift to the opposite signal appears to occur about every

Fig. 3. Distributions of temporal changes in annual mean precipitation for overlapping $30 \mathrm{yr}$ periods. Shown are percentage differences of the individual $30 \mathrm{yr}$ means from the long-term mean (1900-1999). Shaded areas indicate less precipitation, compared to the 1900-1999 mean. The contour interval is $4 \%$ 
30-40 yr, which may be related to the quasi-70-yr oscillation of precipitation in eastern China (Qian et al. 2003a).

3.2. Spring. The largest negative percentage $(-24 \%)$ of spring precipitation (Fig. 4) is observed in NW China (19001929) and then moves southeastward in 1910-1939 and 1920-1949 (Fig. 4A-C). During the period 1930-1959, there are 2 positive centers with $+12 \%$ in $\mathrm{NW}$ China and $+8 \%$ in the central and lower Yangtze Valley. In northern China, the positive center moved eastward from 1940-1969 to 1970-1999. Reversed distributions occurred in the periods 1900-1929 and 1940-1969.

3.3. Summer. The negative and positive percentage centers of summer precipitation are seen for several $30 \mathrm{yr}$ periods (Fig. 5). The negative center $(-8 \%)$ is observed first in NW China (1900-1929) and moves southeastward to central East China (1910-1939, 1920-1949, and 19301959), to the middle and lower Yangtze River (1940-1969), to the southern Yangtze Valley (1950-1979), and to South China (1960-1989). The positive center can be traced in northern China (1930-1959) and then moved southward to the central and lower Yangtze Valley in 1970-1999. The southward shift of negative and positive anomaly centers was characterized by the quasi-70-yr oscillation between the northern and southern parts of China. A large part of East China was dry during the periods 1900-1929 and 1960-1989, as indicated by widespread negative anomalies in summer precipitation (Fig. 5). Both the Yellow and Yangtze River Valleys were dry, while South China was wet in the period 1920-1949. In the periods 19401969 and 1950-1979, the wet anomaly occurred in NW and North China, while the dry anomaly was along the Yangtze River. Dry climate in the Yangtze River Valley but wet anomaly in South China can be identified in the periods 1910-1939 and 1930-1959. The wet anomalies along the central and lower Yangtze Valley and in the northern part of NE China are found in the period 1970-1999.

3.4. Autumn. The southeastward shift of anomaly centers can also be observed for the autumn precipitation (Fig. 6). In the
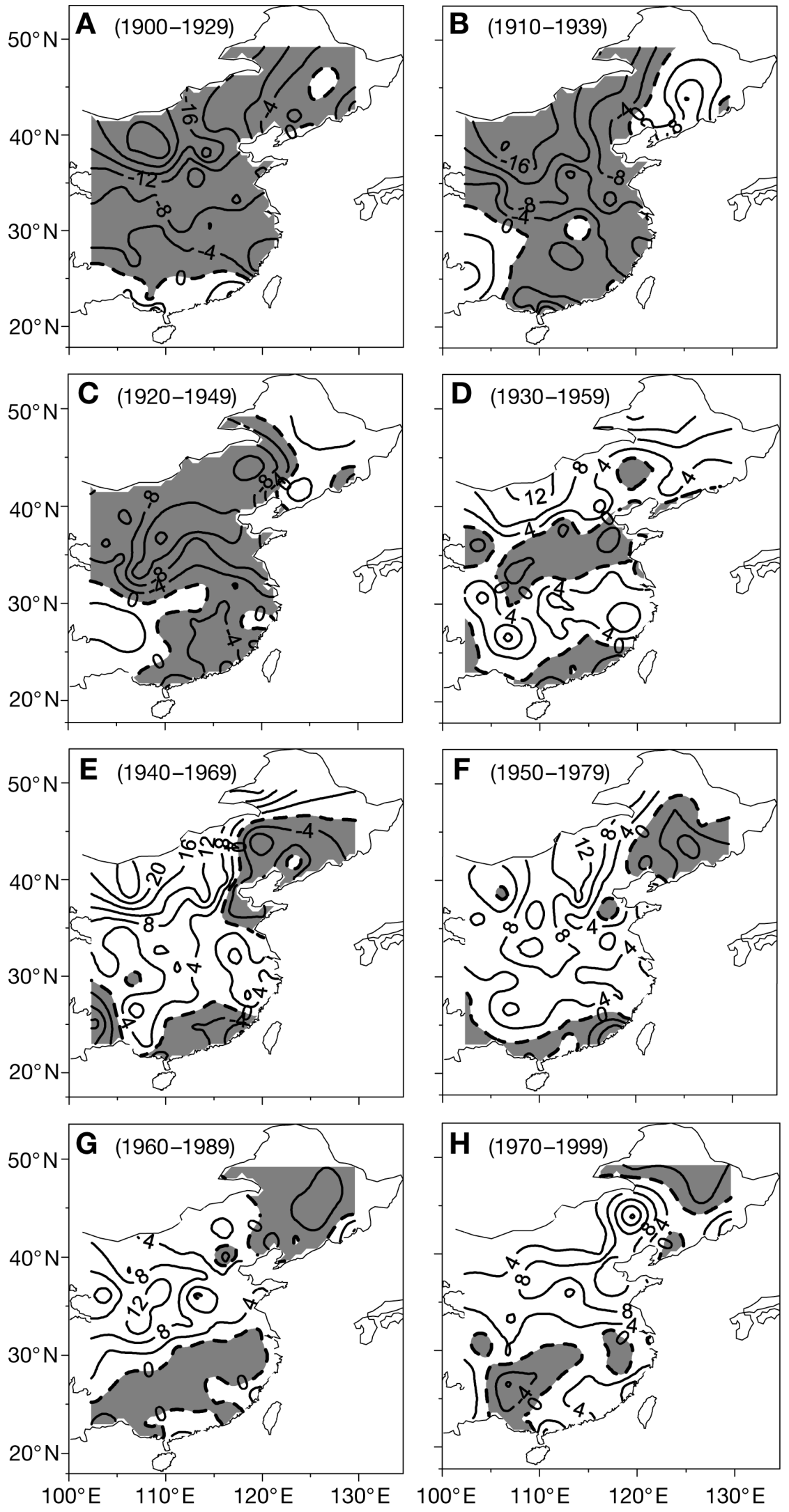

Fig. 4. As in Fig. 3 for spring precipitation 
period 1900-1929, a negative center is observed in the central Yellow River Valley, which then gradually moved southeastward crossing the Yangtze River to South China in 1950-1979. A positive center in NW China in the period 19401969 moved southeastward, ending in the lower Yangtze River Valley in 1970-1999.

3.5. Winter. In winter, an eastward shift of the precipitation anomaly centers can be identified in northern China (Fig. 7). A negative center first appeared in NW China in 1900-1929, moved to the middle Yellow River in 1910-1939, to North China in 1920-1949 and 1930-1959, and to the lower Yellow River in 1940-1969.

\section{REGIONAL PRECIPITATION VARIABILITY}

We divided East China into 6 regions of annual precipitation for describing regional precipitation variability (Fig. 1). Temporal variability for these 6 regions was shown as percentage departure from regional means of annual precipitation (Fig. 8). Considering all 6 regions together annual precipitation was above the longterm mean in the 1950 s and below the long-term mean in the 1920s. The largest variability (>40\%) is found in Regions B (North China) and C (NW China). The abnormally dry climate in the 1920s was widespread, while the wet climate in the 1950s was a dominant feature in northern China (Regions A-C). During the 1960s, a dry climate occurred in the south of the Yangtze Valley (Regions E and F). In NE China, there appear to be $4-5$ oscillations at a regular interval of 20-25 yr. The wettest period in NE China appeared in the 1950s and dry periods in the early 1900s and 1970s. In North China, there were 2 wet periods from the 1880 s to 1890 s and from the late 1940 s to the early 1960 s, while severe dry periods occurred from the 1920 s to the early 1940 s and centered in the 1980s. In NW China, there were 2 dry periods in the 1920s and the 1990s.

The most severe and widespread drought in China was recorded in the 1920s. Since 1922, 9 provinces in northern China had suffered rainfall deficiency associated with high temperature (Qian \&
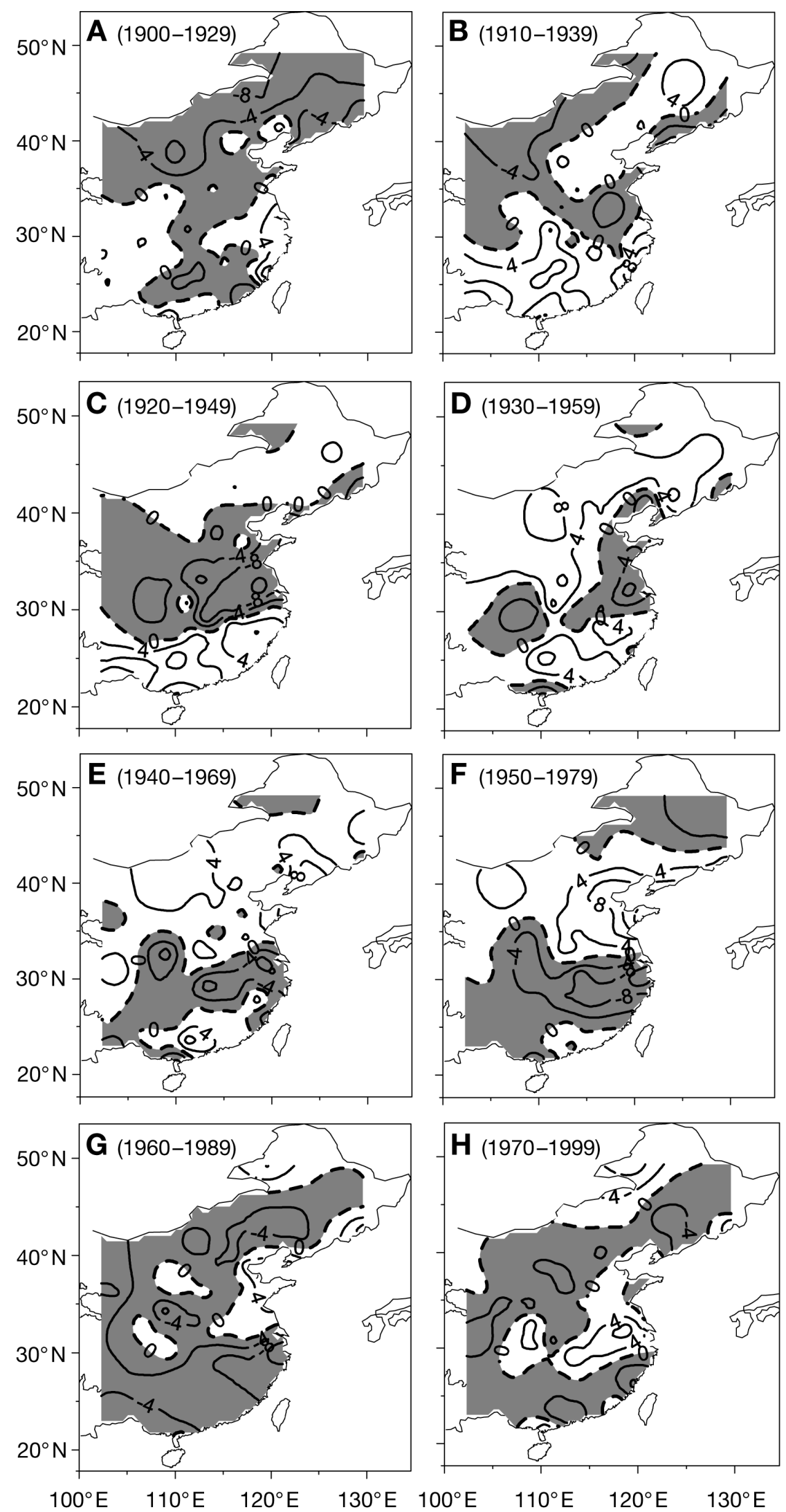

Fig. 5. As in Fig. 3 for summer precipitation 

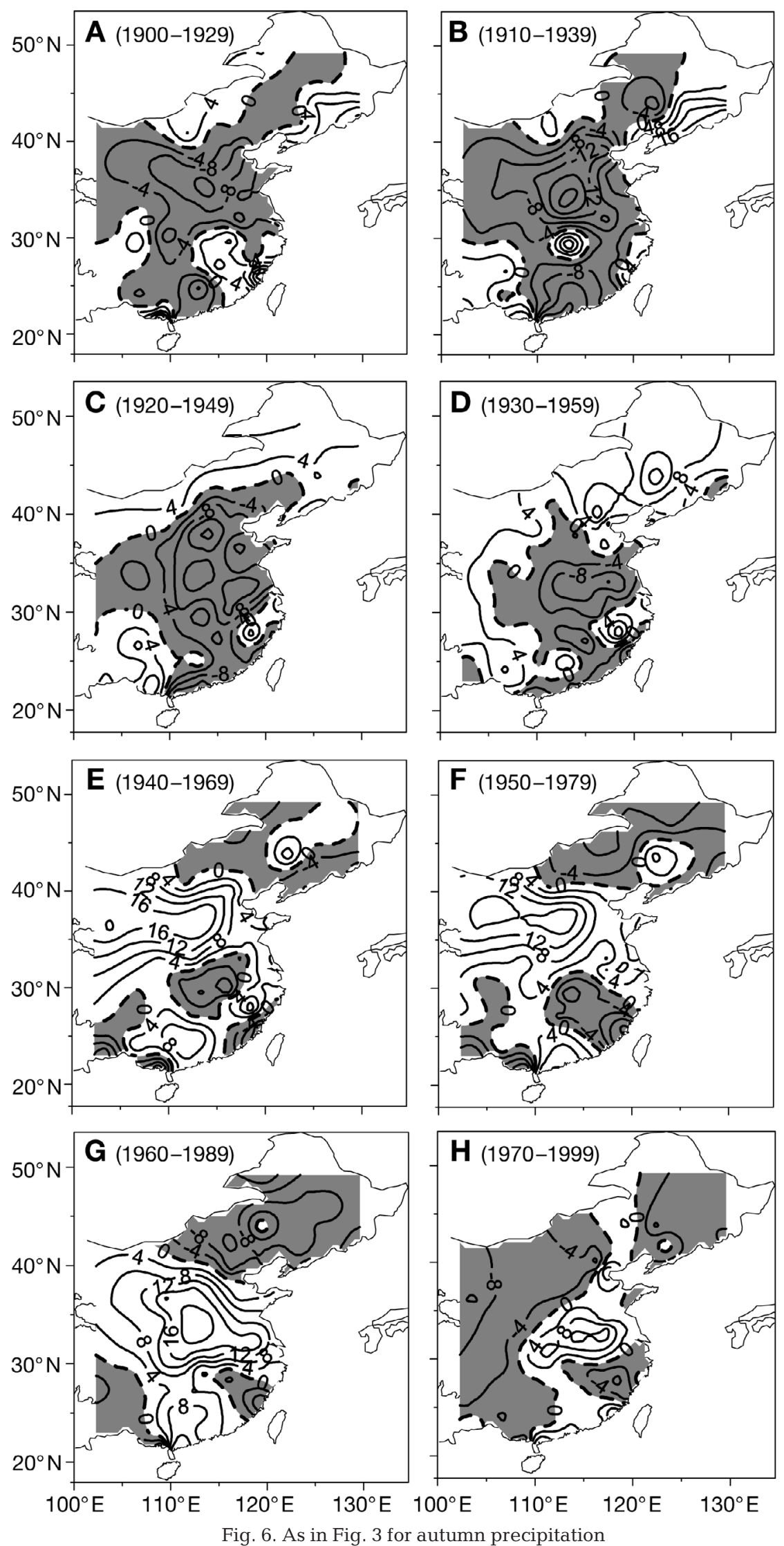

Zhu 2001). The long-lasting drought and repeated crop failures for several years caused severe famine at the end of 1920s in northern China (Zhou et al. 1997): 34 million people were affected and suffered from the drought, and at least 10 million died (Deng 1937). The Sanmenxia gauge in the Yellow River measured the lowest annual runoff during the late 1920s. The low runoff event was also observed at the Hankou gauge $\left(114.1^{\circ} \mathrm{E}, 30.6^{\circ} \mathrm{N}\right)$ in the middle Yangtze River in the late 1920s (Qian et al. 2003a). Another consequence of persistent low precipitation are longterm no-flow periods in the lower Yellow River, which occurred especially in the last decade of the 20th century. The year 1997 had the most severe drought in the last 5 decades in NW China. During that year, the lower reaches of the Yellow River experienced the most extreme hydrological condition in recorded history, with no flow for a total of $226 \mathrm{~d}$, occurring on 13 occasions in 11 months and spanning $700 \mathrm{~km}$ (Zhao et al. 2002).

There is no obvious long-term trend for the summer total precipitation timeseries, but below normal precipitation occurred in the 1920s and from 1970s to 1980s and above normal precipitation in the 1950s and 1990s. The decadal variations of summer precipitation are apparent in several regions in East China. Summer flood occurred in 1954, 1998 and 1999 along the Yangtze River. From NW China to the Yangtze River Valley, dry summer occurred in the 1920s. A wet summer climate was observed in the last decade along the Yangtze River and dry in the Yellow River. Two severe wet periods along the Yangtze River occurred from the late 1900s to the early 1910s and in the 1990s.

The spring precipitation for the period 1900-1999 shows long-term increasing trend over the last century, with a wet interval in the late 1950s and early 1960s. This increasing trend is particularly obvious in northern China. Since the 1980s, dry climate in the spring was apparent south of the Yangtze River and in SW China. In the last $120 \mathrm{yr}$, autumn dry climate was found in 3 periods: the late 1890s, 1920s, and 1990s. The $20 \mathrm{yr}$ dry-wet oscillations of autumn precipita- 

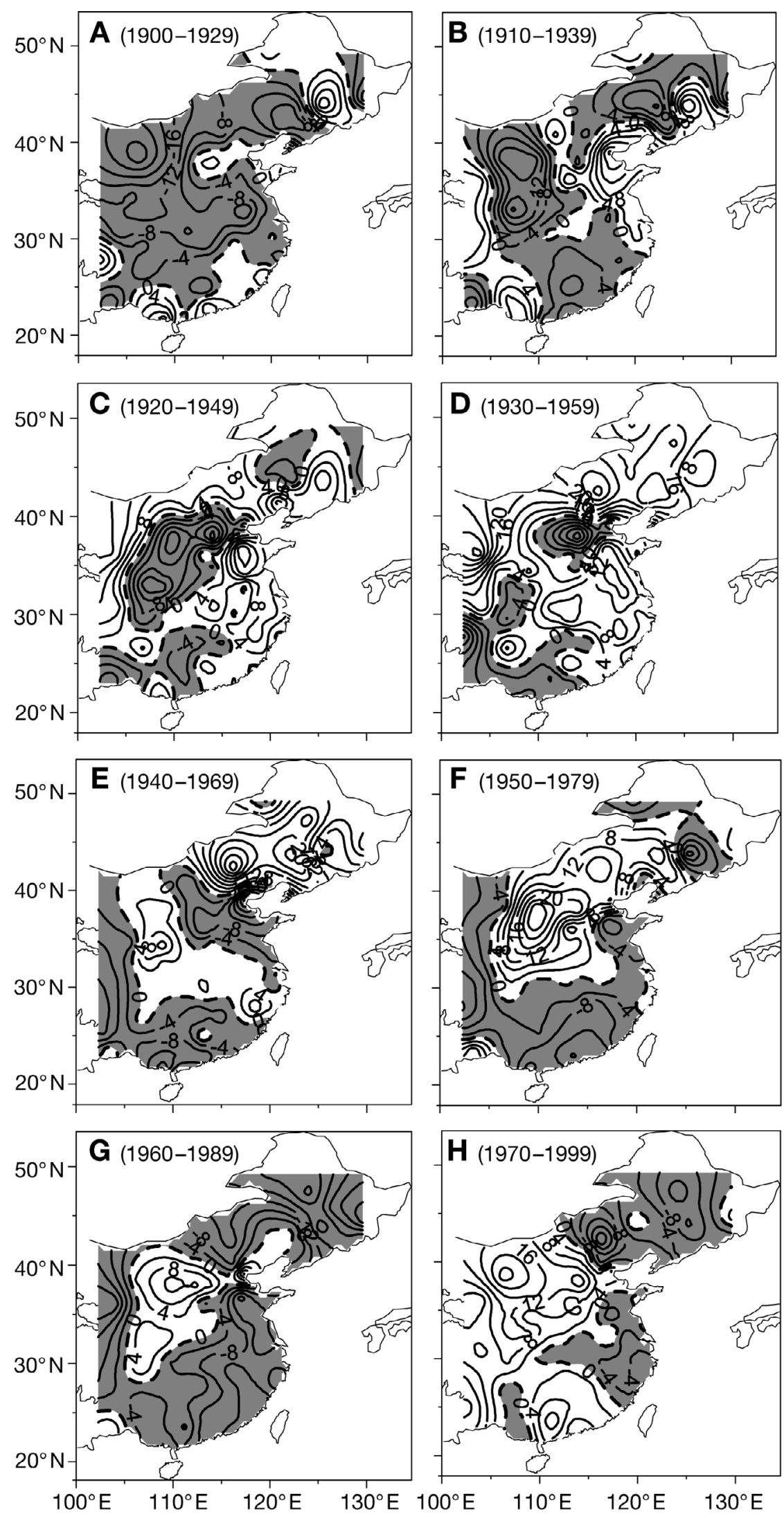

Fig. 7. As in Fig. 3 for winter precipitation tion were predominant in NE China. Since the 1960s, autumn precipitation showed a decreasing trend in northern China.

The largest variability of precipitation (60 to $100 \%$ ) was found in the winter season. The strong interannual variability becomes obvious in the last half century, which may be an observational bias, as there were few winter weather reports in the earlier period. In NE China, abovenormal winter precipitation was found from the late 1950 s to the 1960 s, while there were 3 below-normal periods in the late 19th century, from the late 1930s to the early 1940s, and from the late 1960s to the early 1970s. In North China, an abovenormal winter precipitation is noted in the 1920s. In NW China, a long-term belownormal winter precipitation was found from the 1900s until the early 1940s, followed by 3 oscillations in the last 6 decades. In the year 1990, a severe wet winter was observed in northern China. Along the middle and lower Yangtze River and in SW China, there were 5-6 oscillations in the last 120 yr. An increasing trend of winter precipitation and large interannual variability are found in southern China since the 1980s.

\section{SUMMARY}

Statistical analyses of the newly updated seasonal precipitation time-series from 1880-1999 at 71 sites in East China were used to identify spatial and temporal variability and regional shifts in climate regimes. The updated time-series were based on instrumental precipitation measurements and calibrated historical documents (Wang et al. 2000).

(1) For mean annual precipitation, the largest relative variability of precipitation (>25\%) occurred in northern China. Seasonally, large relative variability in spring $(40-60 \%)$ and winter $(70-90 \%)$ was found in northern China, while low variability of $30-40 \%$ was seen in southern China. In summer, relatively large variability of precipitation $(40 \%)$ was located in the middle Yangtze River and NW China. In autumn, relatively large variability of precipitation was noted in many places except SW China and NE China. 
(2) Over the last century, multidecadal dry and wet climate anomalies tended to first appear in NW China. In the spring and winter seasons, the dry or wet center first appears in NW China and moves eastward to North and NE China. In summer and autumn, the dry or wet center is also first observed in NW China and shifts southeastward to the middle and lower Yangtze Valley and South China. These moving paths suggest multi-decadal dry-wet climate pattern in East China and are consistent with the long-term variations of the East Asian summer monsoon.

(3) East China was divided into 6 regions for examining the temporal evolutions of annual precipitation. The quasi-20-yr oscillation can be found from annual precipitation series during the last century. The series showed that the 1920s were the driest decade in East China during the last $100 \mathrm{yr}$. The regional precipitation variations are different from season to season. In spring, precipitation increased in all regions in East China for the last century. Since the 1920s, increasing regional spring precipitation mainly came from North China and the middle and lower Yellow and Yangtze River Valleys, while a decreasing trend of spring precipitation was observed in SW China in the last 2 decades. Three wet summer periods in East China were concentrated in the 1880s, 1950s and 1990s. Summer precipitation in the Yangtze Valley decreased during the 1940s-1950s and increased trend in the 1990s but reversed trends of summer precipitation were observed along the Yellow River Valley. The severe dry condition in the 1920s was significant in autumn and a decreasing trend was again observed in the last 4 decades. In contrast to autumn precipitation, the winter precipitation had an increasing trend in the last 2 decades.

Fig. 8. Relative variability as a percentage of regional means from the 1880-1999 mean annual precipitation for $(\mathrm{A})$ all regions and $(\mathrm{B}-\mathrm{G})$ regions $\mathrm{A}$ to $\mathrm{F}$ (see Fig. 1 for definitions). The heavy solid line indicates the $11 \mathrm{yr}$ running average of the annual percentage. $(\mathrm{H})$ Annual runoff $\left(\times 10^{7} \mathrm{~m}^{3} \mathrm{yr}^{-1}\right)$ from Sanmenxia gauge station $\left(111.2^{\circ} \mathrm{E}, 34.8^{\circ} \mathrm{N}\right)$ in the Yellow River
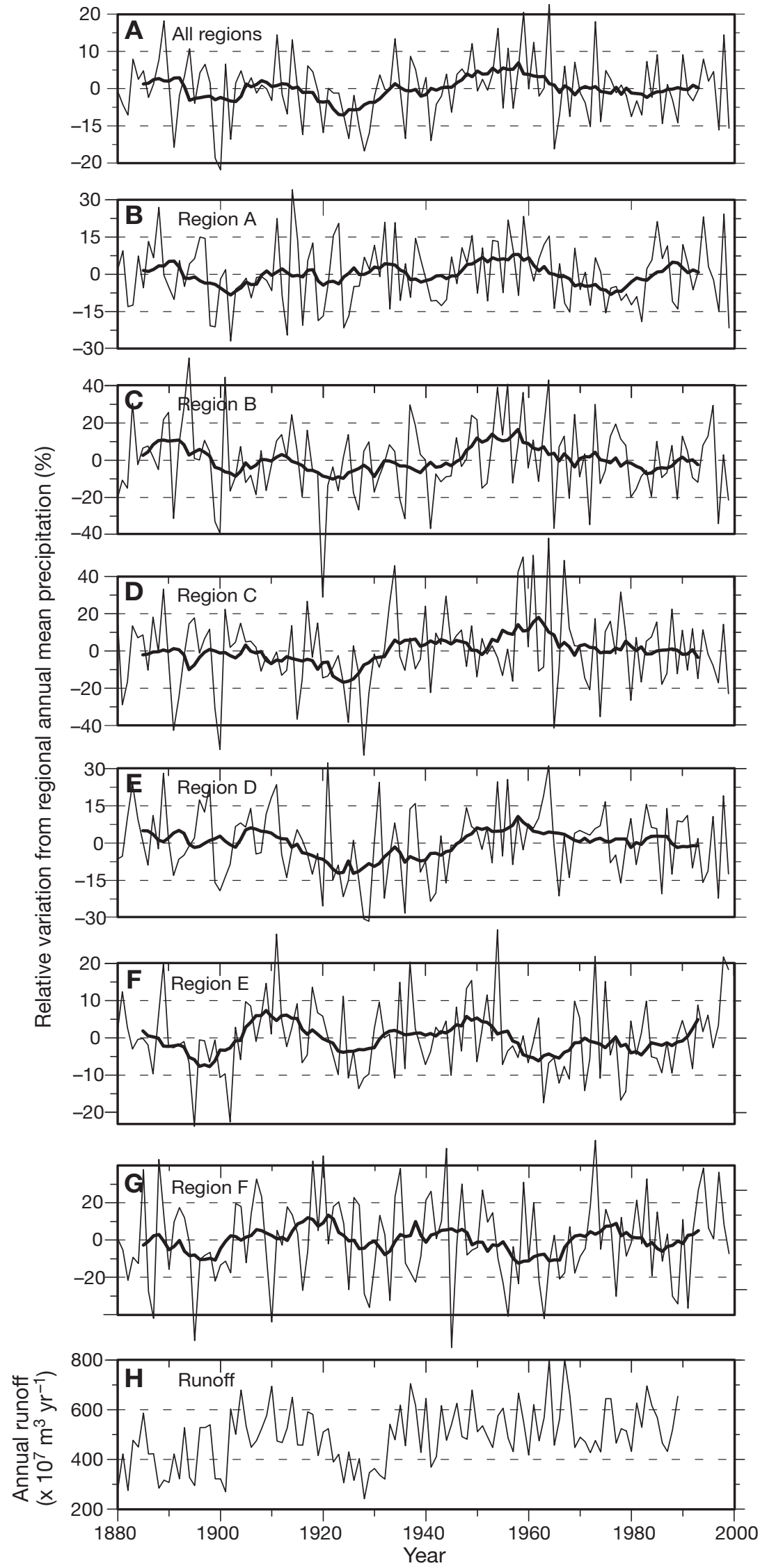
Acknowledgements. The authors thank Professor S. W. Wang for providing the seasonal precipitation data from 1880 to 1999 at 71 sites in East China. We thank 2 journal reviewers and the editor for helpful comments and suggestions that greatly improved the manuscript. This research was supported by the National Basic Research Program of China (No. 2006CB400504) and the National Natural Science Foundation of China (40475032 and 90502001).

\section{LITERATURE CITED}

Damage Report (1995) Report of the damage caused by disaster in China. China Statistical Press, Beijing

Deng YT (1937) History of famine relief in China. Commercial Press, Beijing

Ge QS, Zheng JY, Hao ZX, Zhang PY, Wang WC (2005) Reconstruction of historical climate in China. Bull Am Meteorol Soc 86(5):671-679 DOI:10.1175/BAMS-86-5-671

Gong DY, Ho CH (2002) Summer precipitation shift over Yangtze River Valley in the late 1970s. Geophys Res Lett 29(10):10.1029/2001GL014523

Guo QY, Cai JN, Shao XM, Sha WY (2004) Studies on the variations of East Asian summer monsoon during $\mathrm{AD}$ 1873-2000. Chin J Atmos Sci 28(2):206-215

Ho CH, Kim JH, Lau KM, Kim KM, Gong DY, Lee YB (2005) Interdecadal changes in heavy rainfall in China during the northern summer. Terr Atmos Ocean Sci 16(5):1163-1176

$\mathrm{Hu}$ Q, Feng S (2001) A southward migration of centennialscale variations of drought/flood in eastern China and the western United States. J Clim 15:1323-1328

Hu ZZ (1997) Interdecadal variability of summer climate over East Asia and its association with $500 \mathrm{hPa}$ height and global sea surface temperature. J Geophys Res 102: 19403-19412

Hu ZZ, Yang S, Wu RG (2003) Long-term climate variations in China and global warming signals. J Geophys Res Atmos 108(D19):Art. No. 4614 OCT 11

Liu BH, Xu M, Henderson M, Qi Y (2005) Observed trends of precipitation amount, frequency, and intensity in China, 1960-2000. J Geophys Res 108(D8):Art. No. D08103 APR 20

New M, Hulme M, Jones P (2000) Representing twentiethcentury space-time climate variability. Part II: Development of 1901-96 monthly grids of terrestrial surface climate. J Clim 13:2217-2238

Peterson TC, Vose RS (1997) An overview of the global histor-

Editorial responsibility: James Hurrell,

Boulder, Colorado, USA ical climatology network temperature database. Bull Am Meteorol Soc 78(12):2837-2849

Qian WH, Lin X (2005) Regional trends in recent precipitation indices in China. Meteorol Atmos Phys 90(3-4):193-207, DOI 10.1007/s00703-004-0101-z

Qian WH, Zhu YF (2001) Climate change in China from 1880-1998 and its impact on the environmental condition. Clim Change 50:419-444

Qian WH, Chen D, Zhu YF (2003a) Temporal and spatial variability of dryness/wetness in China during the last 530 years. Theor Appl Climatol 76:13-29

Qian WH, Hu Q, Zhu YF, Lee DK (2003b) Centennial-scale dry-wet variations in East Asia. Clim Dyn 21:77-89

Song J (2000) Changes in dryness/wetness in China during the last 529 years. Int J Climatol 20:1003-1015

Tao S, Chen L (1987) A review of recent research on the East Asian summer monsoon in China. In: Chang CP, Krishnamurti TN (eds) Monsoon meteorology. Oxford University Press, New York, p 60-92

Wang SW, Zhao ZC (1979) Analysis of the drought/flood for the last 500 years in China. Acta Geogr Sin 34(4):329-341 (in Chinese)

Wang SW, Gong DY, Ye JL, Chen ZH (2000) Seasonal precipitation series of eastern China since 1880 and the variability. Acta Geogr Sin 55(3):281-293 (in Chinese)

Weng H, Lau KM, Xue Y (1999) Multi-scale summer rainfall variability over China and its long-term link to global sea surface temperature variability. J Meteorol Soc Jpn 77: $845-857$

Xu Q (2001) Abrupt change of the mid-summer climate in central east China by the influence of atmospheric pollution. Atmos Environ 35(30):5029-5040

Ye JL, Chen ZH, Gong DY, Wang SW (1998) Characteristics of seasonal precipitation anomalies in China for 1880-1996. Q J Appl Meteorol 9(Special Issue):57-64 (in Chinese)

Zhai PM, Zhang XB, Wan H, Pan XH (2005) Trends in total precipitation and frequency of daily precipitation extremes over China. J Clim 18:1096-1107

Zhao CM, Liu YM, Zhang JL, Shi QG (2002) Drought-flood caution records in the 20th century in China. Yellow Hydrological Press, Zhengzhou, p 293-378

Zhou WZ, Zhao CM, Zhou ZX, Lu JY, Zhang Y, Wu ZP (1997) Drought and flood damages in China. China Water Resource Press, Beijing

Zhou YK, Ma ZY, Wang LH (2002) Chaotic dynamics of the flood series in the Huaihe River Basin for the last 500 years. J Hydrol 258:100-110

Submitted: March 27, 2006; Accepted: August 12, 2006 Proofs received from author(s): October 18, 2006 